\title{
Strengthening the early detection of common cancers in the Eastern Mediterranean Region
}

Nasim Pourghazian, ${ }^{1}$ Rengaswamy Sankaranarayanan, ${ }^{2}$ Samar Alhomoud ${ }^{3}$ and Slim Slama4

\begin{abstract}
${ }^{1}$ Technical Officer, Department of Noncommunicable Diseases and Mental Health, World Health Organization Regional Office for the Eastern Mediterranean, Cairo, Egypt. ${ }^{2}$ Senior Visiting Scientist, International Agency for Research on Cancer, Lyon, France \& Senior Medical Advisor, Research Triangle Institute India, New Delhi, India. ${ }^{3}$ Consultant Colorectal Surgeon at King Faisal Specialist Hospital and Research Center, Riyadh, Saudi Arabia \& Chair of The Ethics Committee at International Agency for Research on Cancer (IARC) Lyon, France. ${ }^{4}$ Regional Advisor, Noncommunicable Diseases Prevention, World Health Organization Regional Office for the Eastern Mediterranean, Cairo, Egypt. (Correspondence to: Nasim Pourghazian: pourghaziann@who.int).
\end{abstract}

Citation: Pourghazian N; Sankaranarayanan R; Alhomoud S; Slama S. Strengthening the early detection of common cancers in the Eastern Mediterranean Region. East Mediterr Health J. 2019;25(11):767-768. https://doi.org/10.26719/2019.25.11.767

Copyright @ World Health Organization (WHO) 2019. Some rights reserved. This work is available under the CC BY-NC-SA 3.o IGO license (https:// creativecommons.org/licenses/by-nc-sa/3.o/igo).

Cancer is the fourth leading cause of death in the Eastern Mediterranean Region (EMR) with an estimated 676500 new cases and 419000 cancer deaths in $2018(1,2)$. Population growth, ageing and the rise of risk factors may lead to double the incidence within the coming decades (2). Based on GLOBOCAN 2018 the most common cancers in the region are breast, colorectal, lung, liver and bladder cancer, closely followed by Non-Hodgkin lymphoma and leukemia. The most common cancers among men in the Region are lung (10.4\%), liver (8.4\%) and prostate cancer $(8 \%)$, while the most common cancers among women are breast (34.7\%), colorectal (5.7\%) and cervical cancer (4.6\%) (2).

In 2017, a regional framework on cancer prevention and control was endorsed, guiding policy-makers on how to adopt an integrated public health approach to cancer prevention and control, while taking into consideration the health system building blocks and multi-sectoral integration. The framework proposes strategic interventions divided into six key areas of work across the continuum of care, of which one is specifically on early detection. Another document, "Early Detection of Cancers Common in the Eastern Mediterranean Region," guiding policy-makers on how to prioritize and differentiate between appropriate early detection approaches was published in 2017 (3). Global commitments such as the WHO Global NCD Action Plan 2013-2030 and the recently launched global initiative on cervical cancer elimination highlighted the critical importance of early detection and treatment of noncommunicable diseases (NCDs) to rapidly reduce premature mortality. Moreover, technical consultations and global policy dialogue on the scaling up of early detection are planned to be initiated in 2020 .

Early detection of cancer aims to discover the disease at an early curable stage when treatment is more effective and affordable. The two main strategies for early detection include early diagnosis and screening programmes (4). Early diagnosis is defined as the early identification of cancer in symptomatic patients and is applicable to all contexts and cancers. This contrasts with cancer screening programmes, which seeks to identify the disease in its pre-clinical stage among asymptomatic and seemingly healthy target populations, thus suitable for selected cancers and settings. Screening is much more complex and resource intensive, requiring considerable investment and a strong health care infrastructure to have an impact (5). There is sufficient evidence to support organized, quality assured, population-based screening programmes for breast, colorectal and cervical cancer in countries where the disease burden is high, resources are available and the health system is able to deliver effective services in a timely manner (5-8). On the other hand, poorly organized screening programmes can cause harm to individuals and lead to inappropriate use of health care resources, which in turn can have implications on the rest of the health care system. Thus, it is essential to anticipate the various health system requirements when planning a national early detection strategy in the Region.

To date, most screening activities in the Region remain opportunistic and are in some instances initiated with limited planning and health system assessment, resulting in high costs, inefficiencies and increasing burden on the health services (9). Opportunistic breast, cervical and colorectal cancer screening have been implemented in some EMR countries, but this is still on a small scale since only a limited proportion of the population participate. The 2017 country capacity survey for the prevention and control of NCDs reported that $76 \%$ and $73 \%$ of countries globally had a national screening programme for cervical cancer or breast cancer respectively, and just over a third of the programmes reached up to $10-50 \%$ of the target population - confirming the challenge of ensuring high participation and detection rates (10).

Breast cancer is the most common cancer in all countries of the region, and is associated with risk factors such as obesity and physical inactivity which are highly prevalent among the female population in EMR. Although the age standardized incidence rate of breast cancer for the Region (42.6 per 100000 population) is lower than that of Europe (69.5) and the Americas (66.5), the EMR still has the highest mortality rate of all WHO regions (2). This discrepancy is partially explained by 
the lack of effective early detection mechanisms in the Region and deficiencies in treatment uptake, leading to a significant proportion of breast cancer cases being discovered at a late stage when the condition is less susceptible to available treatment.

Therefore, countries in the Region should make use of available tools and guidance documents to strengthen an early diagnosis approach based on evidence-informed assessments of national cancer burden and health system readiness, while addressing financial, geographical, logistic and sociocultural barriers relevant to the national context. Improving population awareness and primary health care capabilities to suspect and refer breast cancer for timely diagnosis and treatment, while developing adequate human resources and infrastructure to manage breast cancer and other priority cancers amenable to cure is crucial. Countries also need to ensure a robust monitoring and evaluation system that identifies gaps in early diagnosis, assesses quality, programme performance and guides mid-course corrections. Furthermore, preventive strategies such as the use of HPV-vaccination for cervical cancer and tobacco control interventions should be scaled-up. With every third cancer case in adults attributable to eight potentially modifiable risk factors (smoking, alcohol, high BMI, insufficient physical activity, unhealthy diet, suboptimal breastfeeding, infection, air pollution), implementation of strategic population-level preventive interventions are essential but remain underutilized in the EMR (11).

While some of the common cancers in the region, such as lung and liver, are better tackled by primary preventive interventions such as population-level tobacco control measures and vaccination, other cancer forms such as breast, colorectal and cervical cancer can be more effectively managed through adoption of the suitable national early detection strategy. Given the health system resource constraints that most countries in the EMR are facing, countries and policy-makers of the Region should prioritize an early diagnosis approach as a solid foundation before considering the introduction of organized, systematic population-based screening programmes.

\section{References}

1. Kulhánová I, Bray F, Fadhil I, Al-zahrani AS, El-basmy A, Anwar WA, et al. Profile of cancer in the Eastern Mediterranean region : The need for action. Int J Cancer Epidemiol Detect Prev. 2017;47:125-32.

2. Global Cancer Observatory (GLOBOCAN). Estimated number of cancer cases in 2018, Worldwide. Lyon: IARC; 2019 (http://gco. iarc.fr/).

3. WHO Regional Office for the Eastern Mediterranean (WHO/EMRO). Early detection of cancers common in the Eastern Mediterranean Region. Cairo:WHO/EMRO; 2017 (https://apps.who.int/iris/bitstream/handle/10665/258889/emropub_2017_19206. pdf?sequence $=1$ \&isAllowed $=y$ ).

4. World Health Organization. Guide to cancer early diagnosis. Geneva: World Health Organizaation; 2017 (http://apps.who.int/ bookorders).

5. International Agency for Research on Cancer (IARC). Handbooks of Cancer Prevention - Breast Cancer Screening, Volume 15. Lyon: IARC; 2016.

6. International Agency for Research on Cancer (IARC). Handbooks of Cancer Prevention - Colorectal cancer screening, Volume 17. Lyon: IARC; 2019.

7. World Health Organization. Comprehensive cervical cancer control -aA guide to essential practice (2nd edition). Geneva: World Health Organization; 2015 (https://apps.who.int/iris/bitstream/handle/10665/144785/9789241548953_eng.pdf?sequence=1)

8. World Health Organization. WHO position paper on mammography screening. Geneva: World Health Organization; 2014. (https://apps.who.int/iris/bitstream/handle/10665/137339/9789241507936_eng.pdf?sequence=1).

9. Lyons G, Sankaranarayanan R, Miller AB, Slama S. Scaling up cancer care in the WHO Eastern Mediterranean Region. East Mediterr Health J. 2018;24(1):104-110. https://doi.org/10.26719/2018.24.1.104

10. World Health Organization. Assessing national capacity for the prevention and control of noncommunicable diseases - Report of the 2017 global survey. Geneva: World Health Organization; 2018. (https://apps.who.int/iris/bitstream/hand le/10665/276609/9789241514781-eng.pdf?ua=1).

11. Kulhánová I, Znaor A, Shield KD, Arnold M, Vignat J, Charafeddine M, et al. Proportion of cancers attributable to major lifestyle and environmental risk factors in the Eastern Mediterranean region. Int J Cancer. 2019 (Epub ahead of print) 